\title{
Teachers and prospective teachers' conceptions about averages
}

\author{
KARIN LANDTBLOM* and LOVISA SUMPTER \\ Department of Mathematics and Science Education, Stockholm University, Stockholm, Sweden
}

(Received: June 27, 2018; accepted: March 25, 2019)

\begin{abstract}
In this paper, we explore prospective teachers and teachers' conceptions about averages. The results show that when talking about which of the averages that is easiest and hardest to explain, respectively, the two groups differ in their responses. When teachers' motivations most often are based on pedagogical explanations, the prospective teachers indicate conceptions based on personal experiences, often linked to procedures. When studying the conceptions about which of the averages that is most and least useful, the results indicate that there is no difference between the two groups. Mean is considered most useful, similar to what has been reported in previous studies, and mode is considered least useful by both groups. Few of the respondents recognize the mathematical properties of averages, particularly that "usefulness" is linked to which data that is in focus. The implications of the results are discussed.
\end{abstract}

Keywords: averages; conceptions; statistics education; prospective teachers; teachers

\section{INTRODUCTION}

Previous studies focusing on averages are mainly about the conceptualization of mean, median, and mode (e.g., Groth \& Bergner, 2006; Leavy, 2010; Watson \& Moritz, 2000), mean and median (e.g., Jacobbe, 2012; Zawojewski \& Shaughnessy, 2000), mean and mode (e.g., Cooper \& Shore, 2008, 2010), and the mean (e.g., Leavy \& O'Loughlin, 2006; Makar, 2013; Mathews \& Clark, 2003). The studies concern prospective teachers, teachers, or students using different methods, for instance using tasks with or without graphs (Cooper \& Shore, 2008, 2010; Leavy \& O'Loughlin, 2006), observations (Leavy, 2010; Makar, 2013), responses to written items (Groth \& Bergner, 2006; Zawojewski \& Shaughnessy, 2000), or interviews (Jacobbe, 2012; Mathews \& Clark, 2003; Watson \& Moritz, 2000). Given the variety of studies, we see that doing statistics involves different aspects of the subject both "procedural" ones, such as calculating the arithmetic mean, and "conceptual" ones, where the latter one includes being aware of appropriate contexts where the mean is used. The overall conclusion is that both aspects are of importance when teaching and learning statistics, not at least to a teacher (Groth, 2007).

However, looking at a general level, previous research focusing on mathematics teachers' knowledge needed for teaching has emphasized the importance of the affective domain (e.g., Beswick, 2012; Tatto et al., 2008), as well as the interrelationship between teachers' cognitive domain and affective issues (e.g., Barton, 2009). This includes confidence (Beswick, Callingham, \& Watson, 2012). In our review of previous research on teachers and prospective teacher's knowledge of averages, we see that limited studies focus on affective aspects of the conceptualization on averages, the studies that would fall into the "conceptual" category. This lack of research has been recognized before (Estrada, Batanero, \& Lancaster, 2011). In an overview of research in statistics including affect, the studies listed are mainly about affect about statistics, in comparison to mathematics, or affect about teaching statistics compared to other mathematical areas (Groth \& Meletiou-Mavrotheris, 2018). No results are reported about prospective teachers' conceptions about statistics and in particular about averages and thus no comparison with teachers' conceptions is on offer.

What appears to be missing is a further understanding how teachers and prospective teachers perceive these three mathematical concepts, although different but closely linked to each other. Therefore, the aim of the study is to explore prospective teachers and teachers' conceptions about averages. The research questions are: (a) What are the characteristics of the motivations given by prospective teachers and teachers to which of the averages is the easiest or hardest to explain?; (b) What are their expressed conceptions about the usefulness of the averages?; and (c) How do prospective teachers and teachers differ in their responses?

\section{BACKGROUND}

This study focuses on prospective teachers and teachers' conceptions about three mathematical concepts: mode, mean, and median. One could argue that conceptions can be explained as mathematical beliefs (cf. Schoenfeld, 1992), in particular if beliefs are understood as "an individual's

* Correspondence: Karin Landtblom, Department of Mathematics and Science Education, Stockholm University, SE-106 91 Stockholm, Sweden; Phone: +46 81207 6616; Fax: +46 81207 6570; e-mail: karin.landtblom@mnd.su.se

This is an open-access article distributed under the terms of the Creative Commons Attribution-NonCommercial 4.0 International License, which permits unrestricted use, distribution, and reproduction in any medium for non-commercial purposes, provided the original author and source are credited, a link to the CC License is provided, and changes - if any - are indicated. 
understandings and feelings that shape the ways that the individual conceptualizes and engages in mathematical behaviour" (Schoenfeld, 1992, p. 358). Such "understanding" would then incorporate how you view the mathematical concept, for instance how you define different averages depending on whom you are teaching. Another theoretical concept that could encompass this phenomenon is Tall and Vinner's (1981) concept image. Concept image is found to include "all the mental pictures and associated properties and processes" (Tall \& Vinner, 1981, p. 152), therefore including affective aspects of the concepts such as how an individual see the usefulness of different averages.

Given the small number of previous studies focusing on teachers and prospective teachers' view on these three mathematical concepts, in this paper, we choose to talk about conceptions as a more general term. The reason to do so is that we want to be able to grasp more about the topic and not to be limited due to a narrow definition of the unit of analysis. Such limitations would also mean that we would have less studies to draw upon in the background to the study. Therefore, conception is here seen as "a general notion or mental structure encompassing beliefs, meanings, concepts, propositions, rules, mental images, and preferences" (Philipp, 2007 , p. 259), meaning that conceptions may have both affective and cognitive dimensions. In this broad definition, conceptions encompass both beliefs (cf. Schoenfeld, 1992) and mental images (cf. Tall \& Vinner, 1981). Inspired by Beswick et al.'s (2012) inclusion of confidence, we also see this as an element of conceptions as part of preferences. This would incorporate qualities such as how a teacher perceives a mathematical concept being easy/hard to teach, so called teacher's self-efficacy. This has been recognized as an important topic, especially self-efficacy regarding teaching statistical investigations (Harrell-Williams, Sorto, Pierce, Lesser, \& Murphy, 2014). No further results are presented regarding teacher's self-efficacy about averages.

Looking at previous research of different types of knowledge regarding averages, some predictors for conceptual understanding have been identified, for instance, the recognition of averages to be a representation of a data set (Watson \& Moritz, 2000) but simultaneously not confusing mean, median, or mode with each other (Jacobbe \& Carvalho, 2011). Studies have also shown that knowledge is also defined as being able to decide in what situation an average is more suitable to use (Groth \& Bergner, 2006; Zawojewski \& Shaughnessy, 2000). Hence, it is not enough with computational understanding: conceptual knowledge adds a statistical knowledge, the ability to describe, and make sense of data sets (Cai, 1998). A body of research show that teachers often show a lack of conceptual knowledge about averages (e.g., Jacobbe, 2012; Jacobbe \& Carvalho, 2011; Leavy \& O'Loughlin, 2006). This has also been reported regarding prospective teachers (e.g., Groth \& Bergner, 2006; Leavy, 2010; Leavy \& O'Loughlin, 2006) and students e.g., Mathews \& Clark, 2003; Zawojewski \& Shaughnessy, 2000). The results include more cognitive aspects of knowledge, such as not being able to connect procedures with the involved average in a specific situation (Jacobbe, 2012), not recognizing suitable situations for the mean (Leavy \& O'Loughlin, 2006), only relying on computation of the mean (Watier, Lamontagne, \& Chartier, 2011), not only paying attention to the context of the data (Cooper \& Shore, 2008), but also conceptions such as the idea that the mean always is more suitable than the median (Zawojewski \& Shaughnessy, 2000). It has been concluded that "it appears that many students, who complete introductory statistics courses, are unable to understand the idea of the mean" (Garfield \& Ben-Zvi, 2007, p. 383), implying that you need to know more than the procedures. This is in line with previous research emphasizing the need of understanding that many statistical concepts depend on the numerical context (Batanero, Godino, Vallecillos, Green, \& Holmes, 1994). Other study, when discussing eight first-year students' misconceptions of mean, concluded that it appears that students' concept images were in conflict with their expressed concept definition (Mathews \& Clark, 2003). Such a result not only emphasizes the importance of the investigation of affective aspects of conceptual knowledge compared to only asking how an individual defines a concept.

\section{METHODS}

To seek answers to the research questions, we conducted a survey using a questionnaire that was distributed to prospective teachers (for year 4-6) and teachers teaching in year 4-6. The reasons for targeting these two groups are twofold: (a) the Swedish syllabi have it main focus on averages during these years; and (b) although an explorative approach, we still would like to be able to do a preliminary comparison between prospective teachers and teachers, since we think that a comparison can enable us to discuss what could be the result from experience of teaching. The questionnaire consisted of 13 main questions, of which two will be analyzed and discussed in this article, question 7 (a: Which of the averages was easiest to find an explanation to?; b: Motivate you answer.; c: Which of the averages was hardest to find an explanation to?; d: Motivate you answer.) and question 8 (a: Which of the averages is most useful?; b: Motivate you answer.; c: Which of the averages is least useful?; d: Motivate you answer.). The former aims to capture expressed conceptions regarding their own evaluation of which one is easy/hard to explain. This question covers part confidence/self-efficacy, part self-evaluation in relation to the pedagogical perspective of the cognitive matter of these three mathematical concepts. It was located after a question that asked the respondents to provide such pedagogical explanations. Compared to Philipp's (2007) definition of conception, we argue that in the responses, expressed preferences and other affective aspects will be indicated. Question 8 concentrates on the conception of usefulness with the purpose to bring to light whether the respondents disregard the mathematical side of the mathematical concepts and if so, what conceptions about the use of averages they put forward as an explanation of why a certain average is more/less useful than the other two.

The questionnaire was tested in a pilot study with prospective teachers, and the results suggested that the expressed conceptions about mean, median, and mode to a high degree were procedural (Landtblom, 2018). The responses were also more of the students trying to give a definition instead of providing an explanation of a student 
in year 4-6. Therefore, the instrument was altered and in order to illuminate the difference between a definition and an explanation of a student, the updated version of the questionnaire started with three questions asking about definitions of mean, median, and mode. In this study, since we are interested in conceptions of averages, we will not analyze these definitions or the pedagogical explanations. Instead, the focus is on the respondents' motivations why a certain average was easiest/hardest to explain and indicated conceptions about usefulness.

The questionnaire was distributed to teachers and prospective teachers online. The questionnaire was anonymous and with no possibility to trace respondents. The prospective teachers were in the beginning of their third semester (out of eight) in their teacher program, from the same university in a larger city. Although they have had some mathematical courses, they had not yet studied statistics as part of their teacher program. However, they had some experiences from teaching situations and mathematics education at the time, implying that they could transfer some of their pedagogical knowledge to the questions regarding "How to explain?" The response rate was $35 \%$ (27 out of 77 ). The sample of prospective teachers was made out of convenience, a method useful for exploratory research. The teachers were contacted in two ways, through e-mail and through a Facebook group for teachers in year 4-6. This way of sampling could be described as non-probability version of stratified sampling. The respondents share the characteristics being teachers in year $4-6$, but the sample is not random since all respondents who answered volunteered to participate, in total 36 teachers.

Due to the design of the questions, being open-ended and explicitly asking for motivations, some answers invite to be analyzed quantitatively and others qualitatively. An analysis of this kind, using mixed methods, has the ambition to reveal a more comprehensive and descriptive result than only one approach would do (Biesta, 2012). The goal of the analysis is to describe and compare the conceptions about averages, as part of conceptualizations, from the two groups of respondents. For the quantitative analysis, a two-tailed Fisher's exact test was made. The significance of this study is set on a $5 \%$ level. The null hypothesis is that there is no difference between the groups of respondents. However, if $p<.05$, we reject the null hypothesis and the fact that the groups are different is statistically significant. Such a result indicates that the probability to get an answer of the kind is less than $5 \%$ compared to the total number of possible outcomes from the contingency table. The qualitative analysis focused on any similarities or differences between how the two groups motivate their answers. We used inductive thematic analysis where the goal is to find themes within data where a theme should "cohere together meaningfully, while there should be clear and identifiable distinctions between themes" (Braun \& Clarke, 2006, p. 91). We looked for patterns in the responses, in the motivations to the choices that were most/least difficult to explain and most/ least useful. This analysis was conducted by the first author with the second author as a validator.

As a final step, in order to explore any convergence and corroboration, the results from the two analyses and the two groups were compared as a triangulation (cf. Biesta, 2012). The reason to do so was to be able to describe and compare the different conceptions expressed by the two groups.

\section{RESULTS}

When presenting the results, we will start by showing the difference between the two groups regarding the conceptions which of the averages that is easiest/hardest to explain. Then, we further explore this issue using the results from the qualitative analysis including illustrations of the results using motivations given by the respondents. This includes a comparison of the two groups. We will present the results regarding the conceptions of usefulness in the same manner.

\section{Easiest/hardest to explain}

Looking at what is stated easiest and hardest to explain, we can observe some differences between the two groups (Table 1).

As shown in Table 1, the $p$ value is less than .05. Hence, we reject the null hypothesis for both of the two questions. Most teachers state that mode is easiest to explain, whereas the prospective teachers' responses are more evenly spread between the three averages. The same pattern occurs for the prospective teachers when expressing which of the averages they think is hardest to explain. The teachers share their responses between mean (47.2\%) and median (38.9\%). In order to say more about why prospective teachers differ from teachers, we analyzed their written responses. The analysis showed five general themes for all the responses. These are named personal (Pe), pedagogical (Ped), mathematical (Ma), general (Ge), and not relevant (NR). In a motivation, several conceptions could be indicated.

\section{Easiest to explain}

First, we focus on "easiest to explain." The results are presented in Table 2.

Table 1. Which average is perceived easiest/hardest to explain [ $n(\%)]$

\begin{tabular}{|c|c|c|c|c|c|}
\hline & Mean & Median & Mode & Other & FET \\
\hline \multicolumn{6}{|l|}{ Easiest to explain } \\
\hline Prospective teachers & $8(29.6)$ & $8(29.6)$ & $10(37.0)$ & $1(3.7)$ & \multirow[t]{2}{*}{$p<.05$} \\
\hline Teachers & $7(19.4)$ & $4(11.1)$ & $25(69.4)$ & $0(0)$ & \\
\hline \multicolumn{6}{|l|}{ Hardest to explain } \\
\hline Prospective teachers & $5(18.5)$ & $9(33.3)$ & $10(37.0)$ & $3(11.1)$ & \multirow[t]{2}{*}{$p<.01$} \\
\hline Teachers & $17(47.2)$ & $14(38.9)$ & $5(13.9)$ & $0(0)$ & \\
\hline
\end{tabular}

Note. FET: Fisher's exact test. 
Table 2. Themes of conceptions why easiest to explain $[n(\%)]$

\begin{tabular}{|c|c|c|c|c|c|c|c|}
\hline Average & Group & $\mathrm{Pe}$ & Ped & $\mathrm{Ma}$ & $\mathrm{Ge}$ & NR & Total \\
\hline \multirow{2}{*}{ Mean } & PT & 4 & 1 & 3 & 3 & 1 & 12 \\
\hline & $\mathrm{T}$ & 1 & 4 & 1 & 2 & 1 & 9 \\
\hline \multirow[t]{2}{*}{ Median } & PT & 1 & 3 & 6 & 0 & 1 & 11 \\
\hline & $\mathrm{T}$ & 0 & 3 & 3 & 0 & 0 & 6 \\
\hline \multirow[t]{2}{*}{ Mode } & PT & 0 & 3 & 7 & 0 & 2 & 12 \\
\hline & $\mathrm{T}$ & 2 & 15 & 10 & 1 & 4 & 32 \\
\hline \multirow[t]{2}{*}{ Others } & PT & 0 & 0 & 0 & 0 & 1 & 1 \\
\hline & $\mathrm{T}$ & 0 & 0 & 0 & 0 & 0 & 0 \\
\hline \multirow[t]{3}{*}{ Summary } & PT & $5(14)$ & 7 (19) & $16(44)$ & 3 (19) & $5(14)$ & $36(100)$ \\
\hline & $\mathrm{T}$ & $3(6)$ & $22(47)$ & $14(30)$ & $3(6)$ & $5(11)$ & 47 (100) \\
\hline & All & $8(10)$ & $29(35)$ & $30(36)$ & $6(7)$ & $10(12)$ & $83(100)$ \\
\hline
\end{tabular}

Note. Pe: personal; Ped: pedagogical; Ma: mathematical; Ge: general; NR: not relevant; PT: prospective teacher; T: teacher.

As we can see in Table 2, the majority of motivations from the teachers had a pedagogical foundation (47\%) such as descriptions on practical exercises or other pedagogical ideas such as "It is easiest to explain with words not [having to] use examples" [T9, about mode], whereas most of the prospective teachers' arguments, irrespective which average that have been chosen, were based in mathematics (44\%). The theme is illustrated by the following responses:

there is a clear computing procedure in order to get the mean of several numbers [PT23]; it requires more of an estimation competence while the other two requires that you can note and compute with numbers [PT2, about median]; It is not a concept where you have to compute or move around figures. [PT9, about mode]

What these responses have in common is a focus on the mathematical procedure (or lack of) and very little (or nothing) about what the concept is really about, the mathematical properties. This is true for the 14 responses (30\%) from the teachers as well, for instance "If there are an odd number of numbers, the median is the easiest" [T30]. "Easiest" is then not related to the mathematical properties in relation to the task, it is about the procedure.

As an illustration of the other themes, two examples of personal argument are "Because I had good insight about it" [PT13, about mean] and "I think it is most logical" [T36, about mean]. From these statements, we can draw little information about their conceptual knowledge, but there are traces indicating confidence about explaining mean to a student in year 4-6. The theme "General" is mainly created for responses based on everyday use such as "[the one I] use the most in daily life" [PT16, about mean]. An example of the responses categorized as NR is "I don't understand the question" [PT26].

\section{Hardest to explain}

Moving on to which of the averages that the prospective teachers and teacher considered hardest to explain, the statistical analysis showed that the two groups differ in their responses. When analyzing their written responses, we see similar patterns that were presented in Table 2 , namely that higher proportion of teacher motivations in the themes of conceptions focusing on pedagogical issues (40\%). However, for the prospective teachers, the theme "personal" is dominant (43\%; Table 3$)$.

Starting with the prospective teachers and motivations based on personal aspects, we see two patterns within this main theme. The first one is responses saying "I don't have enough knowledge about this particular concept," here illustrated by the following two responses:

I don't really know what it is [PT3, about mode]; Personally, I find median hardest and therefore I find it hardest to explain. My own knowledge fails. [PT4, about median]

There are also responses that use their perceived knowledge about other averages, most often mean, including pedagogical knowledge: "I think I take the mean for granted and haven't found any good explanations for students" [PT14]. What these responses have in common is that they are based in a self-evaluation of their personal knowledge about averages including perceived confidence. It is interesting to note that 8 of the 10 prospective teachers who state that mode is hardest to explain, because they think that they do not understand what mode is. The other two says that they do not understand the question.

Looking instead at the teachers and the main theme "pedagogical," of a total of 16 responses, 7 explanations focus on mean and 6 on median. Two examples about mean are:

To give the students deep understanding you need many types of exercises and open questions [T3]; It is harder to concretize mean than the other two (median and mode). [T12]

These statements indicate that teachers perceive that the different averages have their own pedagogical challenges, here how easy/hard it is to find different types of exercises and tasks, and how easy/hard it is to concretize a particular average. Similar arguments are found when motivating why median is hardest.

The other main theme for the teachers is explanations based on conceptions about the mathematics, $37.5 \%$ of the responses fall into this category. This theme is illustrated by 
Table 3. Themes of conceptions why hardest to explain

\begin{tabular}{|c|c|c|c|c|c|c|c|}
\hline Average & Group & $\mathrm{Pe}$ & Ped & $\mathrm{Ma}$ & $\mathrm{Ge}$ & NR & Total \\
\hline \multirow[t]{2}{*}{ Mean } & PT & 1 & 1 & 2 & 0 & 1 & 5 \\
\hline & $\mathrm{T}$ & 0 & 7 & 9 & 0 & 2 & 18 \\
\hline \multirow[t]{2}{*}{ Median } & PT & 3 & 1 & 6 & 0 & 0 & 10 \\
\hline & $\mathrm{T}$ & 3 & 6 & 5 & 2 & 1 & 17 \\
\hline \multirow[t]{2}{*}{ Mode } & PT & 8 & 0 & 0 & 0 & 2 & 10 \\
\hline & $\mathrm{T}$ & 0 & 3 & 1 & 1 & 0 & 5 \\
\hline \multirow[t]{2}{*}{ Others } & PT & 0 & 0 & 0 & 0 & 3 & 3 \\
\hline & $\mathrm{T}$ & 0 & 0 & 0 & 0 & 0 & 0 \\
\hline \multirow[t]{3}{*}{ Summary } & PT & $12(43.0)$ & $2(7.0)$ & $8(29.0)$ & $0(0)$ & $6(21.0)$ & $28(100)$ \\
\hline & $\mathrm{T}$ & $3(7.5)$ & $16(40.0)$ & $15(37.5)$ & $3(7.5 .0)$ & $3(7.5)$ & $40(100)$ \\
\hline & All & $15(22.0)$ & $18(26.0)$ & $23(34.0)$ & $3(4.0)$ & 9 (13.0) & $68(100)$ \\
\hline
\end{tabular}

Note. Pe: personal; Ped: pedagogical; Ma: mathematical; Ge: general; NR: not relevant; PT: prospective teacher; T: teacher.

the following explanation: "Since the mean often is a number that does not exist in the data, but has to be constructed" [T25]. When analyzing these motivations, the results indicated that both teachers and prospective teachers express conceptions focusing on the procedure, in particular about median and the two cases of odd and even numbers. Examples are:

When you seek the median, at an even number [of observations] you need to put all the figures in line order of sizes and then calculate the mean of this in the middle in order to find the mean [PT6]; Knotty when there is a difference in the procedure dependent if the number of observations are odd or even. [T10]

A third of all the motivations why an average is hardest to explain (34\%) falls into this theme. It appears what they have in common is stressing the problems with the procedures for computing, just as in the case of the median. This could be a sign of perceived lack of understanding of the mathematical properties of the concepts, similar to what was indicated with prospective teachers and the case of mode.

\section{Usefulness}

The results show a substantial share of responses indicating mean is the most useful average with a small majority among the teachers, but with no clear answer with reference to which average is thought of as the least useful (Table 4).

As Table 4 shows, in neither case, we reject the null hypothesis that there is no difference between the groups using at a two-tailed test ( $p$ value $>.05$ ).

\section{Most useful}

Looking at the motivations why, we see that the dominant motivations for most useful are based on an indicated conception concerning "general use," a notion based on general application of mean (Table 5).

The main theme "general" consists of motivations based on a daily and usability perspective, such as "Often occurs in society" [РT2, about mean], "If we think about the weather" [PT21, about median], or "the most common measure in newspapers etc" [T18, about mean]. The majority of these motivations is about mean, 30 of 32 . Similar reasoning can be found in the explanations that has a pedagogical stance, for instance, "Most often used in primary school" [РT20, about median]. What they have in common is a conception that an average is most useful and often in a certain context.

Looking at the other responses, the next main theme is "mathematical" with almost a third of the total explanations. Some examples are:

Taking into account all values [PT24, about mean]; Most fair since the lowest or highest numbers do not affect so much. [T23, about median]

Such responses could be an indication of not understanding the intrinsic mathematical properties of averages, that what is useful depends on the data and the context of the task. Some of the prospective teachers emphasize, just as in the previous questions, the procedure. This is here illustrated by the following comment: "[It is] Good to compute the mean in [any] tasks and learn the algorithm how to do it." [PT3, about mean]. It appears that independent of the task, you should, according to this prospective teacher, compute the

Table 4. Average considered most/least useful $[n(\%)]$

\begin{tabular}{|c|c|c|c|c|c|}
\hline Examined groups & Mean & Median & Mode & Other & FET \\
\hline \multicolumn{6}{|l|}{ Most useful } \\
\hline Prospective teachers & 17 (62.9) & $2(7.4)$ & $3(11.1)$ & $5(18.5)$ & \multirow[t]{2}{*}{$p>.05$} \\
\hline Teachers & $31(86.1)$ & $2(5.6)$ & $0(0)$ & $3(8.3)$ & \\
\hline \multicolumn{6}{|l|}{ Least useful } \\
\hline Prospective teachers & $1(3.7)$ & $9(33.3)$ & $8(29.6)$ & $9(33.3)$ & \multirow[t]{2}{*}{$p>.05$} \\
\hline Teachers & $0(0)$ & $12(33.3)$ & $16(44.4)$ & $8(22.2)$ & \\
\hline
\end{tabular}

Note. FET: Fisher's exact test. 
Table 5. Themes of conceptions most useful $[n(\%)]$

\begin{tabular}{|c|c|c|c|c|c|c|c|}
\hline Average & Group & $\mathrm{Pe}$ & Ped & $\mathrm{Ma}$ & $\mathrm{Ge}$ & NR & Total \\
\hline \multirow{2}{*}{ Mean } & $\mathrm{PT}$ & 3 & 0 & 5 & 8 & 3 & 19 \\
\hline & $\mathrm{T}$ & 1 & 4 & 5 & 22 & 0 & 32 \\
\hline \multirow[t]{2}{*}{ Median } & PT & 0 & 1 & 0 & 1 & 0 & 2 \\
\hline & $\mathrm{T}$ & 0 & 0 & 2 & 0 & 0 & 2 \\
\hline \multirow[t]{2}{*}{ Mode } & $\mathrm{PT}$ & 1 & 1 & 2 & 1 & 0 & 4 \\
\hline & $\mathrm{T}$ & 0 & 0 & 0 & 0 & 0 & 0 \\
\hline \multirow[t]{2}{*}{ Others } & PT & 0 & 0 & 3 & 0 & 2 & 5 \\
\hline & $\mathrm{T}$ & 0 & 0 & 3 & 0 & 0 & 3 \\
\hline \multirow[t]{3}{*}{ Summary } & PT & $4(13)$ & $2(6)$ & $10(32)$ & $10(32)$ & $5(16)$ & $31(100)$ \\
\hline & $\mathrm{T}$ & $1(3)$ & $4(11)$ & $10(27)$ & $22(59)$ & $0(0)$ & 37 (100) \\
\hline & All & $5(7)$ & $6(9)$ & 20 (29) & $32(47)$ & $5(7)$ & $68(100)$ \\
\hline
\end{tabular}

Note. Pe: personal; Ped: pedagogical; Ma: mathematical; Ge: general; NR: not relevant; PT: prospective teacher; T: teacher.

mean. However, a few respondents $(n=8)$ recognize the issue of averages being both context and data bound. Some of the comments are:

\section{None of them say everything. A combination of all three or mean and median or mode. [T27, about other]; Most useful is hard to say, they are good to different things depending what one wants to use them for, but I say mode [PT5, about mode]; It all depends on the field of application! But I would say mean and median is the most useful since I have made it [through life] without [having to use] mode! [PT7, about other]}

The last comment, although acknowledging that averages depend on the data and context, "field of application," the respondent ends with a personal note that he/she has not been needed to use mode in everyday life to date.

\section{Least useful}

If we instead focus on the conception of which average is the least useful, most of the motivations are also in the theme "general," just as in the case of "most useful" (Table 6).

In the responses, we can see that that the conception of an average being considered least useful is partly connected to the respondent's perceived knowledge, for instance "I don't know myself when to use it" [PT17, about median] or "To me, that concept is the hardest" [PT21, about mode]. This is Pe. From the teachers, we found a few pedagogical motivations, for instance:

I think they are all useful. In conversation with the students, one can easily bring everyone, and the students tend to be eager to figure out these values in our own investigations. [T21, about other]

Some prospective teachers also indicate that usefulness depends on the context and the task, here illustrated by the following two responses:

Depends on which context [PT13, about other]; It depends on what one is supposed to do. [PT27, about other]

Most of the motivations, 39\%, are in the theme "general" and involves everyday life, such as "Rarely one hears/reads the term median in the news" [T23, about median] or "It feels like it was not used as often as the mean and median." [PT14, about mode]. These motivations are all besides one about median and mode, and they could be an indication of a conception that there is an idea of absence of useful applications for median or mode in everyday life especially when combined with the results of the previous question, indicating that mean is considered by the majority as the most useful average.

Table 6. Themes of conceptions least useful, $n(\%)$

\begin{tabular}{|c|c|c|c|c|c|c|c|}
\hline Average & Group & $\mathrm{Pe}$ & Ped & $\mathrm{Ma}$ & $\mathrm{Ge}$ & NR & Total \\
\hline \multirow{2}{*}{ Mean } & PT & 1 & 0 & 0 & 1 & 0 & 2 \\
\hline & $\mathrm{T}$ & 0 & 0 & 0 & 0 & 0 & 0 \\
\hline \multirow[t]{2}{*}{ Median } & PT & 3 & 0 & 5 & 1 & 1 & 10 \\
\hline & $\mathrm{T}$ & 1 & 1 & 5 & 6 & 1 & 14 \\
\hline \multirow[t]{2}{*}{ Mode } & PT & 1 & 0 & 1 & 4 & 4 & 10 \\
\hline & $\mathrm{T}$ & 2 & 1 & 2 & 8 & 3 & 16 \\
\hline \multirow[t]{2}{*}{ Others } & PT & 0 & 0 & 0 & 5 & 5 & 10 \\
\hline & $\mathrm{T}$ & 3 & 3 & 0 & 3 & 0 & 9 \\
\hline \multirow[t]{3}{*}{ Summary } & PT & $5(16)$ & $0(0)$ & $6(19)$ & $11(34)$ & $10(31)$ & $32(100)$ \\
\hline & $\mathrm{T}$ & $6(15)$ & $5(13)$ & 7 (18) & $17(44)$ & $4(10)$ & 39 (100) \\
\hline & All & $11(15)$ & $5(7)$ & 13 (18) & $28(39)$ & $14(20)$ & $71(100)$ \\
\hline
\end{tabular}

Note. Pe: personal; Ped: pedagogical; Ma: mathematical; Ge: general; NR: not relevant; PT: prospective teacher; T: teacher. 


\section{DISCUSSION}

As an explorative study, the results indicate that regarding which average that is easiest/hardest to explain, prospective teachers and teachers differ in their responses. The prospective teachers have a rather even distribution between the three averages with a slight overweight on median when choosing which average is easiest to explain. The teachers are more unified in their choice and picked mode. According the prospective teachers, mode is hardest to explain, whereas most teachers opt for mean. Looking at the motivations why, the inductive analysis generated five main themes that were also applicable for the question least/most useful. The themes are personal (Pe), pedagogical (Ped), mathematical $(\mathrm{Ma})$, general $(\mathrm{Ge})$, and not relevant $(\mathrm{NR})$. These themes are very similar to Schoenfeld's (1992) categorization of mathematical beliefs: (a) beliefs about mathematics (e.g., mathematics is based on rules), (b) beliefs about self (e.g., I am able to solve problems), (c) beliefs about mathematics teaching (e.g., teaching is telling), and (d) beliefs about the social context (e.g., learning is competitive). In retrospection, it would have been possible to modify and use Schoenfeld's categories resulting in a deductive approach for the thematic analysis. On the other hand, since the analysis was conducted by the first author who was not aware of Schoenfeld's four categories, our similar themes not only reproduces but also supports his categorizations of beliefs, although here is an extension to encompass conceptions about averages as well.

When looking at the characteristics of the motivations given by prospective teachers and teachers to which of the averages is the easiest or hardest to explain, we see that the two groups of respondents differ. Prospective teachers tend to use motivations based on personal reasons $(\mathrm{Pe})$ mainly concerning their own knowledge while teachers predominantly give pedagogical motivations (Ped) often using arguments from teaching experiences or insights in student's knowledge. It is tempting to conclude that this difference is (only) a reflection of teachers' experience and consequently having more pedagogical know-how to draw upon. It would not be improbable since such proficiency would be part of teachers' confidence (cf. Beswick et al., 2012) or teacher's self-efficacy (Harrell-Williams et al., 2014). The prospective teachers, being relatively new to the profession, are more left to their personal experience when describing their conceptions. However, since we only have responses to a questionnaire and no further data, we suggest this as an area of further investigations in order to confirm such a conclusion.

Of those who pick median as the hardest average to explain, a common conception is that the procedure is the reason why this average is difficult, or as one teacher describes it "Knotty when there is a difference in the procedure dependent if the number of observations are odd or even" [T10]. This difficulty with median has been observed in previous studies (e.g., Garfield \& Ben-Zvi, 2007; Zawojewski $\&$ Shaughnessy, 2000), including the analysis of preservice teachers' knowledge of averages (Groth \& Bergner, 2006). The conclusion from these studies is that one aspect of the complexity with median is that the value is not always a number in the data set and another is the ordering of data. The results of this study add to this prior research body, namely the difficulty of the two different procedures depending if the number of observations is odd or even.

When asking about the usefulness, there is no difference between the two groups according to the statistical analysis: mean is perceived to be the most useful by teachers and prospective teachers. Similar results have been reported previously (cf. Zawojewski \& Shaughnessy, 2000). Analyzing the written responses, we see that the conceptions about usefulness, both most and least, are mainly based on ideas talking about daily life. The motivations contain arguments such as most useful in society, presence in media, and one teacher mentions that mean is most common of the averages at primary level. Mean has been recognized having many applications in everyday life (Batanero et al., 1994). However, it appears that most of the respondents do not recognize averages to be a representation of a data set (cf. Watson \& Moritz, 2000) that you need to be able to decide which average depending on the context (cf. Groth \& Bergner, 2006; Zawojewski \& Shaughnessy, 2000) to be able to describe and make sense of data sets (Cai, 1998). In this study, some of the prospective teachers emphasize the procedure when computing the mean as an argument for mean being most useful, a conception that has been observed earlier (Watier et al., 2011). On a general level, the results indicate conceptions including mentioning procedures in the responses from the prospective teachers. The result of prospective teachers tends to give explanations focusing on the procedures, similar to what was indicated in the pilot study (Landtblom, 2018). Implications of these results would be that if teacher education strives for conceptual knowledge, including both cognitive and affective aspects, such "procedural" conceptions need to be addressed.

Funding sources: No financial support was received for this study.

Authors' contribution: KL made the analysis and both authors contributed to the writing of this empirical article. Both authors had full access to the references and take responsibility for the integrity and accuracy of the inquiry.

Conflict of interest: The authors declare no conflict of interest.

\section{REFERENCES}

Barton, B. (2009). Being mathematical, holding mathematics: Further steps in mathematical knowledge for teaching. In R. Hunter, B. Bicknell, \& T. Burgess (Eds.), Crossing divides: Proceedings of the 32nd annual conference of the mathematics education research group of Australasia (Vol. 1). Palmerston North, NZ: MERGA.

Batanero, C., Godino, J. D., Vallecillos, A., Green, D. R., \& Holmes, P. (1994). Errors and difficulties in understanding 
elementary statistical concepts. International Journal of Mathematical Education in Science and Technology, 25(4), 527-547. doi:10.1080/0020739940250406

Beswick, K. (2012). Teachers' beliefs about school mathematics and mathematicians' mathematics and their relationship to practice. Educational Studies in Mathematics, 79(1), 127-147. doi:10.1007/s10649-011-9333-2

Beswick, K., Callingham, R., \& Watson, J. (2012). The nature and development of middle school mathematics teachers' knowledge. Journal of Mathematics Teacher Education, 15(2), 131-157. doi:10.1007/s10857-011-9177-9

Biesta, G. (2012). Mixed methods. In J. Arthur, M. Waring, R. Coe, \& L.V. Hedges (Eds.), Research methods and methodologies in education (pp. 147-152). London, UK: Sage.

Braun, V., \& Clarke, V. (2006). Using thematic analysis in psychology. Qualitative Research in Psychology, 3(2), 77-101. doi:10.1191/1478088706qp063oa

Cai, J. (1998). Exploring students' conceptual understanding of the averaging algorithm. School Science and Mathematics, 98(2), 93-98. doi:10.1111/j.1949-8594.1998.tb17398.x

Cooper, L. L., \& Shore, F. S. (2008). Students' misconceptions in interpreting center and variability of data represented via histograms and stem-and-leaf plots. Journal of Statistics Education, 16(2), 1-13. doi:10.1080/10691898.2008.11889559

Cooper, L. L., \& Shore, F. S. (2010). The effects of data and graph type on concepts and visualizations of variability. Journal of Statistics Education, 18(2), 1-16. doi:10.1080/10691898. 2010.11889487

Estrada, A., Batanero, C., \& Lancaster, S. (2011). Teachers' attitudes towards statistics. In C. Batanero, G. Burrill, \& C. Reading (Eds.), Teaching statistics in school mathematics Challenges for teaching and teacher education (pp. 163-174). Dordrecht, The Netherlands: Springer.

Garfield, J., \& Ben-Zvi, D. (2007). How students learn statistics revisited: A current review of research on teaching and learning statistics. International Statistical Review, 75(3), 372-396. doi:10.1111/j.1751-5823.2007.00029.x

Groth, R., \& Meletiou-Mavrotheris, M. (2018). Research on statistics teachers' cognitive and affective characteristics. In D. Ben-Zvi, K. Makar, \& J. Garfield (Eds.), Springer international handbook of research in statistics education (pp. 327-355). Cham, Switzerland: Springer.

Groth, R. E. (2007). Toward a conceptualization of statistical knowledge for teaching. Journal for Research in Mathematics Education, 38(5), 427-437. doi:10.2307/30034960

Groth, R. E., \& Bergner, J. A. (2006). Preservice elementary teachers' conceptual and procedural knowledge of mean, median, and mode. Mathematical Thinking and Learning, 8(1), 37-63. doi:10.1207/s15327833mt10801_3

Harrell-Williams, L. M., Sorto, M. A., Pierce, R. L., Lesser, L. M., \& Murphy, T. J. (2014). Validation of scores from a new measure of preservice teachers' self-efficacy to teach statistics in the middle grades. Journal of Psychoeducational Assessment, 32(1), 40-50. doi:10.1177/0734282913486256

Jacobbe, T. (2012). Elementary school teachers' understanding of the mean and median. International Journal of Science and
Mathematics Education, 10(5), 1143-1161. doi:10.1007/ s10763-011-9321-0

Jacobbe, T., \& Carvalho, C. (2011). Teachers' understanding of averages. In C. Batanero, G. Burrill, C. Reading, \& A. Rossman (Eds.), Teaching statistics in school mathematics challenges for teaching and teacher education (pp. 199-209). Dordrecht, The Netherlands: Springer.

Landtblom, K. K. (2018). Prospective teachers' conceptions of the concepts mean, median and mode. In H. Palmér \& J. Skott (Eds.), Students' and teachers' values, attitudes, feelings and beliefs in mathematics classrooms (pp. 43-52). Cham, Switzerland: Springer.

Leavy, A. M. (2010). The challenge of preparing preservice teachers to teach informal inferential reasoning. Statistics Education Research Journal, 9(1), 46-67.

Leavy, A., \& O'Loughlin, N. (2006). Preservice teachers understanding of the mean: Moving beyond the arithmetic average. Journal of Mathematics Teacher Education, 9(1), 53-90. doi:10.1007/s10857-006-9003-y

Makar, K. (2013). Predict! Teaching statistics using informal statistical inference. Australian Mathematics Teacher, 69(4), 34-40.

Mathews, D., \& Clark, J. (2003). Successful students' conceptions of mean, standard deviation, and the Central Limit Theorem (Unpublished paper). Retrieved from http://citeseerx.ist. psu.edu/viewdoc/download?doi=10.1.1.446.6077\&rep=rep1\& type $=$ pdf

Philipp, R. A. (2007). Mathematics teachers' beliefs and affect. In F. K. Lester, Jr. (Ed.), Second handbook of research on mathematics teaching and learning (Vol. 1, pp. 257-315). Charlotte, NC: Information Age.

Schoenfeld, A. H. (1992). Learning to think mathematically: Problem solving, metacognition, and sense making in mathematics. In D. Grouws (Ed.), Handbook of research on mathematics teaching and learning (pp. 334-370). New York, NY: MacMillan.

Tall, D., \& Vinner, S. (1981). Concept image and concept definition in mathematics with particular reference to limits and continuity. Educational Studies in Mathematics, 12(2), 151-169. doi:10.1007/BF00305619

Tatto, M. T., Schwille, J., Senk, S. L., Ingvarson, L., Peck, R., \& Rowley, G. (2008). Teacher Education and Development Study in Mathematics (TEDS-M): Conceptual framework. East Lansing, MI: Teacher Education and Development International Study Center, College of Eduaction, Michigan State University.

Watier, N. N., Lamontagne, C., \& Chartier, S. (2011). What does the mean mean? Journal of Statistics Education, 19(2), 1-20. doi:10.1080/10691898.2011.11889615

Watson, J. M., \& Moritz, J. B. (2000). The longitudinal development of understanding of average. Mathematical Thinking and Learning, 2(1-2), 11-50. doi:10.1207/S15327833 MTL0202_2

Zawojewski, J. S., \& Shaughnessy, J. M. (2000). Mean and median: Are they really so easy? Mathematics Teaching in the Middle School, 5(7), 436-440. 